\title{
A Review of Studies on Neuromarketing: Practical Results, Techniques, Contributions and Limitations
}

\author{
Vitor Costa Rozan Fortunato \\ Business Administration at the University of São Paulo (USP), Brazil \\ E-mail: vcrfortunato@gmail.com
}

Janaina de Moura Engracia Giraldi (Corresponding author)

University of São Paulo (USP), Brazil

Av. Bandeirantes 3900, Monte Alegre, Ribeirão Preto (SP). Brazi

CEP: $14040-905$

Tel: 55-(16)-3602-4970Ｅ-mail: jgiraldi@usp.br

Jorge Henrique Caldeira de Oliveira

University of São Paulo (USP), Brazil

Av. Bandeirantes 3900, Monte Alegre, Ribeirão Preto (SP). Brazi

CEP: 14040-905. Tel: 55-(16)-3602-0193Ｅ-mail: jorgecaldeira@usp.br

Received: March 8, 2013 Accepted: March 21, 2014 Published: April 24, 2014

doi:10.5296/jmr.v6i2.5446

URL: http://dx.doi.org/10.5296/jmr.v6i2.5446

\begin{abstract}
This article surveyed the main neuromarketing techniques used in the world and the practical results obtained. Specifically, the objectives are (1) to identify the main existing definitions of neuromarketing; (2) to identify the importance and the potential contributions of neuromarketing; (3) to demonstrate the advantages of neuromarketing as a marketing research tool compared to traditional research methods; (4) to identify the ethical issues involved with neuromarketing research; (5) to present the main neuromarketing techniques that are being used in the development of marketing research; (6) to present studies in which neuromarketing research techniques were used; and (7) to identify the main limitations of neuromarketing. The results obtained allow an understanding of the ways to develop, store,
\end{abstract}




\section{Macrothink

retrieve and use information about consumers, as well as ways to develop the field of neuromarketing. In addition to offering theoretical support for neuromarketing, this article discusses business cases, implementation and achievements.

Keywords: Neuroeconomics (D87), Marketing (M31). 


\section{Introduction}

Unconscious mental processes are major influences in people's deliberation. Among the newest techniques for the measurement of marketing stimuli are neuroimaging techniques, which make an image of the patient's brain using non-invasive means. When used in marketing to understand consumer behaviour in relation to markets and commercial trade, these methods are called neuromarketing techniques (Lee, Broderick \& Chamberlain, 2007).

The use of neuromarketing activities has aroused some controversy. On one hand, critics of the subject believe that the use of such techniques would affect consumers' ability to choose not to consume marketed products, leaving the individuals unable to resist such efforts and making them easy targets for the company's campaigns (Wilson, Gaines \& Hill, 2008). On the other hand, defenders of neuromarketing activities, such as Lindstrom (2009a, 2009b) and Dooley (2010), discuss the benefits deriving from the technique to both consumers and organisations. According to these authors, consumers would benefit from the creation of products and campaigns directed to them and would have their decisions facilitated rather than manipulated, while organisations would save large portions of their budgets that are currently used on inefficient and ineffective campaigns, ensuring greater competitiveness and improvements to customers. There is yet another segment of researchers who believe that neuromarketing would be much more science fiction than reality because it is impossible to find people with identical thoughts in the world, as thought is changeable and varies according to personal experiences, values and character (Hubert, 2010).

From the context outlined, this article seeks to survey the main neuromarketing techniques used in the world and the main practical results obtained. Specifically, the objectives are (1) to identify the main existing definitions of neuromarketing; (2) to identify the importance and the potential contributions of neuromarketing; (3) to demonstrate the advantages of neuromarketing as a marketing research tool compared to traditional research methods; (4) to identify the ethical issues involved with neuromarketing research; (5) to present the main neuromarketing techniques that are being used in the development of marketing research; (6) to present studies in which neuromarketing research techniques were used; and (7) to identify the main limitations of neuromarketing.

Although studies on this topic were first conducted in the early 1990s, research in the area is still scarce and inconclusive due to high costs and the need for specialised equipment. However, neuromarketing offers new approaches that, if incorporated into other methodologies, may lead to very interesting effects and could expand the results of marketing strategies in different segments. Organisations can be encouraged to develop market research with the use of neuroimaging techniques for product development, the choice of channels, and pricing and communication decisions.

\section{Methodology}

The field of neuromarketing is fairly new and of great interest to marketing researchers (Morin, 2011, Dinu, Tannase, Dinu \& Tannase, 2010). This exploratory research used the 
technique of content analysis. This technique was described by Bardin (1977) as a set of techniques for the analysis of communications that use systematic procedures and generate a description of the messages' contents.

This research was conducted in two stages. The first step comprised a search for introductory information about the theme in non-academic articles, blogs, academic articles and websites of neuromarketing companies. The non-academic magazines selected were Forbes, The Guardian, the New York Times, The Washington Post, the Los Angeles Times and The Times. The marketing blogs were selected by means of Google's blog search tool. The blogs that contained articles explaining the concept of neuromarketing were selected. These blogs were Neurosciencemarketing Brandsala, Fast Company, Eulogy and RW Connect. Regarding academic articles, introductory articles about the subject were chosen (Lee et al., 2007, Ariely \& Berns, 2010, Morin, 2011). This first step culminated with a general understanding of the theme and the determination of new areas of exploration for the next phase. A recurring point in the articles was the definition of neuromarketing as a new technique for market research.

In the second step, only peer-reviewed academic articles were analysed. To access the content of the articles, the EBSCOhost research platform was used; this platform provided access to over 375 databases. Because neuromarketing is described as a marketing research engine for which it is important to study consumers' behaviour, the following keywords were used: neuromarketing, marketing research and consumer behaviour. In total, 23 articles were read.

The next phase of the analysis consisted of encoding and categorising the documents selected (Bardin, 1977). At this point, semantic elements present in the documents were identified and grouped into defined categories. After reading the articles, seven categories were established based on the criteria of exclusivity, homogeneity, relevance, objectivity and productivity (Bardin, 1977).

\section{Presentation of Results}

The results from the content analysis technique are presented, grouped into the identified categories: definition of neuromarketing, importance of neuromarketing to marketing studies, advantages of neuromarketing over traditional methods of research, ethical issues of neuromarketing, neuromarketing techniques, studies carried out with the application of neuromarketing, and the limitations and downsides of neuromarketing.

\subsection{Definition of Neuromarketing}

The first reports of the use of neuromarketing techniques came out in June 2002. Specifically, an advertising company from Atlanta (USA), Brighthouse, announced the creation of a department for the use of functional magnetic resonance images (fMRI) to conduct marketing research (Fisher, Chin \& Klitzman, 2010). Even before the technique received the prefix "Neuro", some companies already used neurophysiologic techniques, such as electroencephalography (EEG), to solve marketing problems (Fisher et al., 2010). 
However, with advances in technology, neuromarketing techniques have been used to explore consumers' preferences (Murphy, Illes \& Reiner, 2008). This potential to analyse consumer preferences attracted great interest among marketing research companies. In addition to the interest of the companies in exploiting this market niche, the theme raised curiosity among academic researchers and left some individuals in society uncomfortable (Murphy et al., 2008; Fisher et al., 2010; Lee et al., 2007).

Among the texts analysed, many conceptions of neuromarketing were found. Neuromarketing was described as a research field (Murphy et al., 2008), a field of neuroscience (Perrachione \& Perrachione, 2008), a field of study (Lee et al., 2007 and Eser, Isin \& Tolon, 2011), a part of marketing (Fisher et al., 2010), an interconnection of perception systems (Butler, 2008), a scientific approach (Senior \& Lee, 2008), a subarea of neuroeconomics (Hubert \& Kenning, 2008) and a distinct discipline (Garcia \& Saad, 2008). As to its purpose, some authors see neuromarketing mainly as a means of acquiring scientific knowledge (Lee et al., 2007; Murphy et al., 2008; Fisher et al., 2010; Butler, 2008; Senior \& Lee, 2008; and Eser et al.; 2011), while others view neuromarketing more as a potential tool for commercial marketing (Perrachione \& Perrachione, 2008; Hubert \& Kenning, 2008; Fugate; 2007; Orzán, Zara \& Purcarea, 2012; Green \& Holbert, 2012; Vecchiato, Kong, Maglione, \& Wei, 2012).

Despite the differences in the a'uthors' views, it is possible to observe that some notions about neuromarketing are convergent. Among the most recurring themes in the category "definition of neuromarketing" were the understandings of neuromarketing as the measurement of brain activities; a research tool; research on consumers' behaviour; a field belonging to neuroscience; a marketing tool; the measurement of emotions and psychological processes; a commercial technique; the analysis of physiological and cognitive processes related to the nervous system; and a form of representing behaviours in images and colours.

The relationship between the field of study of neuromarketing and cerebral activity is evident in the very etymology of the word. Even so, many authors reaffirm this relationship. Murphy et al. (2008), for instance, say that companies are emerging that provide information about consumer preferences based on the brain. Butler (2008), Senior \& Lee (2008), Hubert \& Kenning (2008) and Morin (2011), on the other hand, associate neuromarketing with a neuroscience technique that identifies the cortical regions responsible for consumers' behaviour.

Neuromarketing is also described as a research tool that provides direct observations of brain reactions during marketing stimuli (Hubert \& Kenning, 2008). According to certain researchers, the brain is a black box that hides consumers' emotions and preferences (Marci, 2008; Javor, Koller, Lee, Chamberlain \& Ransmayr, 2013; Fugate, 2007 and Green \& Holbert, 2012), and neuromarketing works as a window that unveils and gives access to these emotions (Green \& Holbert, 2012; Ohme \& Matukin, 2012; Fisher, Chin \& Klitzman, 2010). When obtaining insights from the brain processes of individuals, researchers will be able to understand, assess and predict the consumers' behaviour (Fisher et al., 2010, Hubert \& Kenning, 2008; Perrachione \& Perrachione, 2008). 
Neuromarketing was also recurrently defined as the neuroscience of consumers (Babiloni, 2012; Ohme \& Matukin, 2012). However, some authors emphasise the difference between the two fields. Fisher et al. (2010) classify neuroscience more broadly as a neuroscientific field that studies consumers, whereas neuromarketing is defined as the simple application of these results to administrative practices. Lee et al. (2007) make clear the distinction between the terms: neuromarketing can be defined as the application of neuroscientific methods to analyse and understand human behaviour in relation to markets and marketing trades.

Other definitions approach neuromarketing as a field resulting from the association between two or even more sciences. According to Senior \& Lee (2008), neuromarketing consists of the marketing research domain based on social psychology, econometrics and social sciences. Page (2012) represents neuromarketing as the convergence between neuroscience, experimental psychology and experimental economics, while Garcia \& Saad (2008) and Hubert \& Kenning (2008) associate neuromarketing with the sciences of consumer behaviour and cognitive neuroscience, i.e., consumer behavioural sciences and neurobiology, respectively. However, the vast majority of articles approach neuromarketing as the connection between neuroscience and marketing (Hubbert \& Keening, 2008; Garcia \& Saad, 2008; Lee et al., 2007; Fisher et al., 2010; Ohme \& Matukin, 2012; Senior \& Lee, 2008; Fugate, 2007; Butler, 2008; Morin, 2011; Page 2012; Perrachione \& Perrachione 2008 and Vecchiato et al., 2012).

Many authors still use the terms "study of brain imaging" (Hubert \& Kenning, 2008; Perrachione \& Perrachione, 2008; Babiloni, 2012; Reynolds, 2006; Garcia \& Saad, 2008; Green \& Holbert, 2012), "study of neuroimaging” (Eser et al., 2011 and Vecchiato et al., 2012), and "neuro-technology" (Murphy et al., 2008 and Fisher et al., 2010) to refer to neuromarketing (Perrachione \& Perrachione, 2008; Green \& Holbert, 2012; Javor et al., 2013; Orzán et al., 2012; Fugate, 2007 and Morin, 2011). This usage most likely occurs because fMRI is the most prominent technique under the academic and market spotlights, although the neuromarketing studies identified in this work go beyond brain imaging.

In this broad definition approach, several authors provide more elaborate explanations of neuromarketing. For example, some authors report neuromarketing as a way of revealing the cognitive emotional processes (fear, motivation, recognition, well-being and reward) underlying human conscience (Lee et al., 2007; Murphy et al., 2008 and Butler, 2008). Fugate (2007) approaches the topic so as to convey the notion of neuromarketing in two ways (simple and elaborate). He asserts that neuromarketing travels between the emotional and rational parts of the person and that it is a technique that makes it possible to show that the physical and the psychological are co-dependent through images that record the rational and emotional responses to marketing stimuli.

Although the field of neuromarketing makes room for different understandings and observations, it is obvious that the definitions are inter-related. Therefore, a comprehensive definition that lists the main points of recurrent neuromarketing in the readings can be inferred. Thus, neuromarketing can be described as a field of research that creates a bridge between the fields of neuroscience and marketing (Butler, 2008; Senior \& Lee, 2008 and 
Hubert \& Kenning, 2008). It has the purpose of establishing relations between marketing stimuli, the brain areas in which these stimuli were processed and the physiological consequences related to the nervous system, so that such areas can be associated with cognitive, psychological and emotional processes and can generate an understanding about the consumer (Lee et al., 2007, Murphy et al., 2008 and Senior \& Lee, 2008).

\subsection{Importance of neuromarketing to marketing studies}

Eser et al. (2011) indicate that neuromarketing uses state-of-the-art resources in brain scanning to understand the consumer buying process. Schneider \& Woolgar (2012) claim that neuromarketing is the newest medium used by marketing researchers to understand consumer behaviour. In fact, understanding consumer behaviour is the most recurrent purpose found in the literature reviewed. The second major important contribution of neuromarketing studies is to understand how consumers make choices during the purchase process. Lee et al. (2007) claim that neuromarketing has become a popular technology to establish the probability and non-probability of purchasing decisions.

Neuromarketing has also been identified as a way of shaping companies' marketing strategies (Eser et al., 2011). Publicity and advertising have been described as the areas of marketing that have benefited the most from neuromarketing techniques. Neuromarketing makes it possible to identify advertising elements that trigger positive feelings (Senior \& Lee, 2008, Fugate, 2007 and Ohme \& Matukin, 2012). In addition, it helps avoid elements that should not be present in the communication, such as elements that cause consumer aversion to the products. It also helps with the selection of visual and sound features, as well as the timing and selection of appropriate media (Fugate, 2007). Neuromarketing has also the ability to identify consumers' needs and, in this way, develop more useful and pleasant products (Eser et al., 2011).

Branding or brand positioning strategies can also be enriched with the aid of neuromarketing. Branding research is engaged in examining how brand information affects decision-making (Hubert \& Kennng, 2008). Neuromarketing can answer this question with a study to determine which neural processes are involved in the brain during the processing of brand information (Hubert \& Kenning, 2008). The potential of neuromarketing to adjust strategies of pricing and product development is demonstrated by Lee et al. (2007) and Senior \& Lee (2008).

Finally, neuromarketing is formed by a group of techniques that seek to identify the brain areas activated during a marketing stimulus and the cognitive processes that occur in those areas, as well as the various related biological markers. Therefore, neuromarketing has great potential to identify the causes of purchasing disorders such as compulsivity (Senior \& Lee, 2008; Garcia and Saad, 2008; Fugate, 2007 and Fisher et al., 2010). Other possible applications of neuromarketing include the development of more effective social campaigns, such as the encouragement of the use of seat belts in cars or smoking cessation (Orzán et al., 2012). 


\subsection{Neuromarketing and Traditional Research Methods}

Neuromarketing is recommended as an important and revolutionary form of marketing research. Fisher et al. (2010) assess neuromarketing as a type of qualitative research that produces graphic and quantifiable results. Bercea (2013) explains that there is difficulty in classifying the research in this new area as qualitative or quantitative and that the equipment types used and the research protocol adopted are the determinants of this classification. Regardless, the importance of neuromarketing lies in its ability to assess emotional processes. Thus, the technique provides access to richer and less biased marketing insights than other traditional research techniques, such as surveys, focus groups and qualitative research (Murphy et al., 2008; Hubert \& Kenning, 2008; Eser et al., 2011 and Page, 2012).

The vast majority of reviewed articles mentioned the advantages that neuromarketing has over traditional marketing techniques. In most articles, the ability of neuromarketing to access and assess information beyond the level of human consciousness was the most cited topic. This ability puts neuromarketing ahead of other research techniques because, according to some authors, the purchase process happens subconsciously (Butler, 2008; Hubert \& Kenning, 2008; Fugate, 2007; Fugate 2008; Page, 2012; Morin, 2011 and Orzán et al., 2012).

The second most cited topic in this category was the inability of individuals to self-assess. Lee et al. (2007) state that it is very difficult for individuals to express their feelings and other subjective factors. In addition, individuals usually cannot explain the origin of and reason for certain behaviours (Hubert \& Kenning, 2008) because emotions are quite complex and often the individual is not aware of the reason for them. In a further challenge to marketing, the individual may not be aware of even experiencing a specific emotion (Murphy et al., 2008).

The inability to self-assess is not the only problem faced in research; individuals are sometimes unwilling to collaborate in research. Individuals tend to transmit incorrect information when the topic is very sensitive or when they feel the need for social acceptance (Hubert \& Kenning, 2008). Thus, the responses obtained are not genuine; they are filtered by the interviewee's consciousness before being reported (Hubert \& Kenning, 2008). Neuromarketing represents the opportunity to overcome these obstacles, as research participants do not have control over the information collected (Butler, 2008; Hubert \& Kenning, 2008 and Fugate, 2007). Another advantage of neuromarketing is the speed and simultaneity of information collection. Some techniques of neuromarketing, such as electroencephalography and magnetoencephalography, can measure the responses of the consumer at the same time that they are exposed to the marketing stimuli (Hubert \& Kenning, 2008; Lee et al., 2007, Fugate, 2007 and Ohme \& Matukin, 2012). With this feature, the researchers can determine exactly which elements of the marketing strategy should be reinforced or discarded.

In the face of these specific characteristics of neuromarketing, the majority of the texts consider this form of marketing research more valuable than focus groups and in-depth interviews (Lee et al., 2007; Murphy et al., 2008; Butler, 2008; Hubert \& Kennoing, 2008; Eser et al., 2011; Fugate, 2007; Fugate, 2008 and Page, 2012). However, despite all the 
excitement about neuromarketing, it should be used in parallel with traditional methods of research. Individuals not only act according to their feelings, they consider the expectation of reward to make a decision in the short and long-term. The combination of both research techniques will ensure more valuable insights into consumers' preferences and the purchase process (Hubert \& Kenning, 2008).

\subsection{Ethical Issues in Neuromarketing}

In the same way that the techniques of neuromarketing raise excitement among companies, they also raise controversy related to ethical issues. Among the texts reviewed, the main ethical issue involving neuromarketing is related to the violation of consumers' privacy. Neuromarketing techniques may have the ability to read consumers' minds (Hubert \& Kenning, 2008; Murphy et al., 2008; Senior \& Lee, 2008; Perrachione \& Perrachione, 2008; Fugate, 2007 and Javor et al., 2013).

Thus, companies would be able to identify and easily trigger mechanisms that induce consumer purchasing behaviour (Lee et al., 2007; Senior \& Lee, 2008; Hubert \& Kenning, 2008 and Javor et al., 2013). Consumers, therefore, would become transparent to the companies, which, at any moment, could invade their private thoughts (Fugate, 2007 and Green \& Holbert, 2012). Another ethical question of neuromarketing lies in the use of the technique for commercial purposes (Lee et al., 2007; Senior \& Lee, 2008; Eser et al., 2011; Fugate, 2007 and Morin, 2011). In examining the cognitive processes related to individuals' consumption preferences, companies acquire great power to influence the purchase decision (Murphy et al., 2008 and Fisher et al., 2010). Many texts cite the lack of ethics related to the possibility of neuromarketing creating irresistible ads and products (Lee et al., 2007; Fisher et al., 2010 and Fugate, 2007). Neuromarketing would then represent a major threat to the autonomy of consumers because it would remove their defence mechanisms (Lee et al., 2007; Murphy et al., 2008; Fisher et al., 2010; Senior \& Lee, 2008; Eser et al., 2011 and Fugate, 2007).

The issues mentioned above relate to ethics involving the principles of neuromarketing. The institutions that apply neuromarketing, how it is applied and the audience surveyed are also grounds for criticism. Among the texts analysed, four indicated the existence of ethical dilemmas involving the application of neuromarketing by academics and physicians or the conduction of neuromarketing studies within universities (Fisher et al., 2010; Fugate, 2007; Javor et al., 2013 and Dinu et al., 2010).

Dinu et al. (2010) show that to many people, universities are a place to acquire new knowledge, as opposed to the potential for neuromarketing to influence consumers. Other authors also say that neuromarketing has raised criticism because there are physicians and academics working in marketing research companies (Fisher et al., 2010 and Fugate, 2007). According to Dinu et al. (2010), possible damage to the health of participants or negative aspects of marketing research can be hidden and, therefore, the results would be biased.

Some authors say that companies should disclose the procedures and results of their research to avoid accusations of irresponsible behaviour (Murphy et al., 2008; Fisher et al., 2010 and 
Senior \& Lee, 2008). Consent from participants should also be obtained before studies are conducted (Senior \& Lee, 2008). The protection of vulnerable populations is also part of the concern regarding neuromarketing (Murphy et al., 2008; Senior \& Lee, 2008; Eser et al., 2011; Fugate, 2008 and Javor et al., 2013). Murphy et al. (2008) commented on the need to regulate the use of neuromarketing techniques on children and other vulnerable groups, such as people with neurological diseases or pathological disorders, people sensitive to advertisements and legally protected groups.

Finally, a concern that appeared in some texts was whether neuromarketing causes consumption disturbances. Lee et al. (2007) cite shopping addiction and over-consumption as problems associated with neuromarketing. In the face of all of the ethical issues involving neuromarketing, a solution proposed by various authors for better regularisation and acceptance of the technique was the adoption of an ethics code for neuromarketing (Murphy et al., 2008; Hubert \& Kenning, 2008; Ezer et al., 2011; Morin, 2011 and Butler, 2008).

\subsection{Neuromarketing Techniques}

Neuromarketing can be characterised as a new scientific field, essentially an interdisciplinary field that seeks to connect studies in marketing with neuroscience (Morin, 2011). The area of neuroscience, in turn, is also interdisciplinary, in that it joins fields such as chemistry, computer science, physics, medicine, psychology and other related areas. There is difficulty in defining precisely what does or does not constitute neuroscience. Among the works included in neuroscience are studies on brain lesions, studies of the nervous system (not only the brain), studies of the genetic and cell structure of the brain and its neural circuits (Pickersgill, 2013).

The scope of neuromarketing techniques must, therefore, take advantage of this diversity in neuroscience research lines, and studies should not be restricted only to the brain or to the central nervous system but should include all of the areas and physiological and cognitive processes. This scope is reflected in the diversity of techniques that should be considered as neuromarketing techniques: from physiological aspects such as perspiration, electrical conductivity of the skin, hormonal and neurotransmitter changes, movement and dilation of the pupil, movements of muscles (body and face), to even the understanding of complex cognitive aspects, such as the functional activity of specific regions of the brain by means of the analysis of different markers such as electrical waves, cerebral metabolism and its blood flow. This bridge between several lines of neuroscience and marketing allows each of these techniques to have enhanced or reduced applicability to respond to different problems that traditional marketing techniques cannot respond to, or respond to only partially.

Among all of the techniques, new and old, the ones that drew the most attention were the techniques that used brain imaging, and the results of these studies had great impact in both academia and business. One of the first studies that demonstrated this potential was conducted in Harvard in the late 1990s using some fairly invasive equipment called PET-SCAN (Zaltman, 1997). Another important milestone project used another technique that also draws considerable attention, functional magnetic resonance, which is costly but not invasive equipment (McClure et. al, 2004). 
If no area of the brain underwent changes after having been exposed to an advertising stimulus, then this stimulus was not successful. However, if the stimulus caused organic modifications in a region, it can be inferred that there is a correlation between advertising and the activated emotion (Fugate, 2007). It is flippant, though, to say that a specific area of the brain that lights up during the investigations does so because an image triggered certain emotions and patterns of consumption, as different emotions depend on different combinations of activations of neural substrates (Marcus, 2012).

Each of the techniques has advantages and disadvantages, often measuring variables that are complementary to better understand a marketing problem. Therefore, to obtain an effective result with neuromarketing technologies, it is advisable and productive to use combined techniques whenever possible. There are three types of neuromarketing techniques: those that measure the metabolic activity in the brain or related to it, those that measure electrical activity in the brain and those that do not measure brain activity. The main neuromarketing techniques are, currently, the following:

- Functional magnetic resonance imaging (fMRI): the advantage of this technique is its ability to measure deeper and smaller structures of the brain, i.e., with high spatial resolution. Along with the technique of electroencephalography, it is the most employed technique to measure brain activity in the field of neural science. However, the use of this technique is expensive, the equipment is not portable, and the environment makes it difficult to conduct the experiment. This technique requires a delay of 6 to 10 seconds to record the processing of neurons, which represents a great disadvantage with respect to several marketing stimuli because these numbers constitute low temporal resolution (Ariely \& Berns, 2011).

- Electroencephalography (EEG): in this technique, electrodes that measure the brain waves associated with different states of stimuli are placed on an individual's scalp through bands or helmets, and these waves can be measured at small intervals up to 10,000 times per second (Morin, 2011). In addition to having the advantages of being more widely available, being less invasive and cheaper, EEG presents greater validity in the measurement of emotional styles and the detection of psychopathologies (Kline, 2004). This technique features the possibility of synchronisation with the stimuli, and the equipment is portable. The weakness of this technique concerns the measurement of deeper brain structures; it can only record more superficial electrical signals. Therefore, in contrast to fMRI, EEG features high temporal resolution and low spatial resolution. 
- Positron emission tomography (PET): a technique with validity and spatial resolution similar to those of fMRI. However, radioactive particles (positrons) must pass through the participant for the collection of results, making this technique highly invasive and difficult to use in neuromarketing (Lin, Tuan \& Chiu, 2010).

- Magnetoencephalography (MEG): this technique is based on the expansion and mapping of the magnetic field created through neural activities, electrochemical signals between neurons. Similarly to electroencephalography, magnetoencephalography has excellent temporal resolution; however, its spatial resolution, while not ideal for measuring subcortical areas and deeper areas in the brain, is superiot to that of EEG (Morin, 2011). In contrast to EEG, when conducting MEG research, individuals use hyper-sensitive sensors to measure the electromagnetic field without contact with the scalp. The cost of the acquisition of the necessary equipment and of the magnetoencephalography session is very high, which contributes to the greater popularity of EEG than MEG (Crease \& Robert, 1991).

- Eye tracking: increasingly used along with other techniques such as EEG and fMRI. Advantages, this method is able to measure the focus of consumers' attention, the pattern of visual behaviour of fixations of the gaze, dilation of the pupils, focus, and microfocus; in addition, the equipment is portable. Among the main disadvantages is the fact that it is not possible to understand what emotions are associated with the areas that were the focus of attention, and not deducting, automatically, that focus necessarily represents higher visual attention. Some of the data of interest to marketing in relation to this technique are the time that the subject spends focusing on the object of study, the measurement of the pupils, the areas and the frequency of observation of users in the stimuli presented (Nenad, 2011).

- Facial recognition (or electromyography): a technique still not largely used in neuromarketing that consists of measuring facial muscle movements that are imperceptible to the human eye through electrodes placed on the muscles of the mouth (zygomaticus minor and major) and on the occipitofrontal and orbicularis muscles to check the type of emotion (happiness, sadness, indifference, pain, etc.) (Melillo, 2006). Among its advantages, the 
following can be emphasised: high spatial resolution, growing credibility for use in the analysis of different affective reactions to visual stimuli, reactions of taste, smell and hearing, human interactions and behaviours. One disadvantage is that the electrodes fixed on the face may inhibit some facial movements. Another important disadvantage for use in neuromarketing is the double meaning of certain expressions, which invalidates a standardisation of single expressions correlated with specific emotions, restricting studies of some more specific emotional reactions (Jones \& Beer, 2009).

- Cardiovascular parameters: this approach records the heart rate and its variability, blood pressure, interaction between heart beats and pulse transition time to infer emotional and attention states of the research subjects (Lindstrom, 2009b).

- The galvanic skin response: this technique measures the objective excitation caused by an emotionally relevant stimulus. The central nervous system is directly connected to the reactions recorded on individuals' hands, and this method is able to identify the neural responses that precede certain emotions, such as happiness, sadness, fear, anger, disgust and indifference (Banks et al., 2012).

\subsection{Practical Applications}

Neuromarketing has generally been used to objectively identify consumers' preferences. Although companies are reluctant to disclose their studies of how to improve marketing strategies, several practical studies on neuromarketing were cited in the reviewed texts. Many of the studies were related to marketing communications, like the ones by Lee et al. (2007) and by Fisher et al. (2010).

Another study demonstrated that the presence of celebrities or people considered physically beautiful in advertisements activates a brain area involved in the process of recognition and creation of trust. Therefore, the conclusion would be that famous or attractive people influence consumers' preferences, resulting in the purchase decision (Hubert \& Kenning, 2008). Pictures of attractive women activated the area of reward and well-being in the brains of heterosexual men. This area is similarly activated when people are exposed to pictures of children and puppies (Hubert \& Kenning, 2008).

Perrachione \& Perrachione (2008) stated that irrelevant messages reduce consumers' positive responses to a product and that those advertising elements that lead consumers to relate to themselves cause positive responses. Another study also showed that expressions of fear and danger activate a brain region that is responsible for the removal of behaviour (Hubert \& Kenning, 2008). These discoveries help companies to modify and select their advertisements 
to include elements that help the brand to be more easily remembered or assist in the retention of consumers' attention (Lee et al., 2007; Perrachione \& Perrachione, 2008; Eser et al., 2011).

According to Fugate (2007), neuromarketing helps companies identify elements that are neurologically engaging in a TV ad. Companies assess the images, phrases, sound effects and music to develop advertising campaigns that are more appealing to consumers (Fugate, 2007). Ohme and Matukin (2012) say that there are three ways in which neuromarketing can assist in the development of advertisements: (1) referential analysis, which seeks to determine the best way to talk about products and brands in a commercial; (2) vertical analysis, in which the advertisement is decomposed into images and sounds to identify which advertising element is more powerful and the types of emotion caused in the consumers; and (3) horizontal analysis, in which different versions made for the same commercial are compared, and the impacts that each one has in the brain activity of participants are measured.

Another use of neuromarketing that is widely reported is in the development of products and services according to the desires of consumers (Fugate, 2008). One of the most frequently mentioned cases among the authors was the experiment ordered by the Daimler-Chrysler company to evaluate car models preferences (Lee et al., 2007; Fisher et al., 2010; Garcia \& Saad, 2008; Eser et al., 2011; Fugate, 2007). In this study, fMRI results showed that areas of the brain linked to reward system and well-being were activated by products that have earned reputation as a symbol of status, luxury and social dominance (Hubert \& Kenning, 2008).

The texts also indicated that neuromarketing techniques are quite effective for pricing, sales and promotion decisions. An interesting phenomenon happens with the determination of prices. A similar price level can be regarded in two different ways by the consumer. A high price for a given category of products, for example, can be perceived as a feeling of loss and, therefore, prevent consumers from purchasing them (Hubert \& Kenning, 2008 and Javor et al., 2013). Alternatively, a high price for a given product may be understood as an indicator of quality and improve the value of the product and, therefore, increase the likelihood of purchase.

A frequently cited study concerns the differences in the prices of wine, showing the role of price in the perception of product quality. The study presented wine samples with different prices, and it was requested that the wines be assessed according to preference, while brain activity was measured by a fMRI device. The brain areas linked to the reward system showed higher activity when individuals believed to be drinking the most expensive wines (Perrachione \& Perrachione; Garcia \& Saad, 2008; Hubert \& Kenning, 2008).

Research on neuromarketing has also been intensely used to determine branding strategies. For example, it was found that brain areas related to the reward system are more activated by brands that evoke self-identification in consumers (Perrachione \& Perrachione, 2008). Another aspect associated with brands that neuromarketing can assist with is the definition of brand names and logo elements (Perrachione \& Perrachione, 2008). 
Neuromarketing was also used to understand the mechanisms underlying consumption loyalty. In a study using fMRI, consumers had to choose the retail brands they would like to buy from. When consumers were purchasing a brand to which they were loyal, the ventromedial prefrontal cortex was activated (Hubert \& Kenning, 2008). This area is associated with the reward system.

Finally, some studies have demonstrated what factors lead consumers to choose certain brands and products (Lee et al., 2007; Garcia \& Saad, 2008). When viewing the brain areas activated by different brands and products, researchers predict what feelings and emotions are correlated and can predict the choices consumers will likely make (Lee et al., 2007).

\subsection{Limitations of Neuromarketing}

Similarly to any other new science, neuromarketing suffers from limitations and the mistrust of the public. According to the texts surveyed, the main limitation of neuromarketing is a lack of credibility of information (Murphy et al., 2008; Fisher et al., 2010; Perrachione \& Perrachione, 2008; Hubert \& Kenning, 2008; Eser et al., 2011; Fugate, 2007; Morin, 2011 and Javor et al., 2013). Currently, a wave called "neuromania" encompasses several fields of knowledge. Javor et al. (2013) and Fisher et al. (2010) say that many sciences use the power of the prefix 'neuro' to overstate and legitimise their results.

Javor et al. (2013) explain that the phenomenon they term "neuroculture" refers to the creation of new science branches by combining neuroscience with other fields of science, arts or humanities, such as neurophilosophy or neurotheology. The same occurs with marketing. With the excitement of neuromania, scientists try to provide explanations for certain consumer behaviours and actions, always based on neurological processes (Javor et al., 2013). However, the results hardly change or add to the results obtained by traditional research methods (Hubert \& Kenning, 2008 and Senior \& Lee, 2008).

Few studies about neuromarketing have been published, and little information is available (Lee et al., 2007; Fisher et al., 2010; Eser et al., 2011 and Fugate, 2008). The great majority of the information is published by neuromarketing companies or academics who work in these enterprises (Javor et al., 2013). As a result, the findings can be biased to the benefit of the companies themselves, putting the credibility of these findings at risk. Another factor that affects the credibility of science is the methodologies applied. Senior \& Lee (2008) say that neuromarketing, as well as other forms of marketing research, is based on statistical data to prove its validity. As different statistical procedures may lead to different results and the rejection of certain hypotheses, neuromarketing companies can influence the results of the research (Marci, 2008).

Many authors also say that because it is a very complex science (the study of brain processes related to emotions), little can be generalised or stated with certainty (Murphy et al., 2008; Fisher et al., 2010; Senior \& Lee, 2008 and Hubert \& Kenning, 2008). In fact, the uniqueness of individuals influences the regions where they process certain emotions and how they do so (Lee et al., 2007; Perrachione \& Perrachione, 2008, Hubert \& Kenning, 2008 and Fugate, 2007). 
The moment and the situation in which an individual receives marketing stimuli also cause the stimuli to be processed differently (Fugate, 2007 and Lee et al., 2007). For example, if the individual receiving the stimuli is in a calm environment, such as in a laboratory of a marketing research company, the activated areas of the brain will be different than if they were in a purchase environment evaluating the options in the midst of many others (Lee et al., 2007). Therefore, an important limitation reported in many texts is the lack of a model that shows the areas of the brain activated concomitantly with the emotions felt by the individual (Butler, 200 and Senior \& Lee, 2008).

In addition, even if neuromarketing could identify the exact emotion processed by the individual, the reason why a given stimulus triggered the emotion would not be revealed (Butler, 2008; Perrachione \& Perrachione, 2008, Hubert \& Kenning, 2008 and Eser et al., 2011). Another limitation is the difficulty of developing experiments. Among the difficulties are the costs of neuromarketing and regulations regarding the performance of neuromarketing research (Hubert \& Kenning, 2008). Because of these costs, individual researchers cannot develop their research without the support of companies (Hubert \& Kenning, 2008). This fact limits the amount of studies and the unbiased nature of the information. As for the regulations, some countries require government approval to carry out this type of research (Babiloni, 2012 and Hubert \& Kenning, 2008).

\section{Final Considerations}

This study had the following purposes: identifying the main existing definitions of neuromarketing; identifying the importance and the potential contributions of neuromarketing; demonstrating the advantages of neuromarketing as a marketing research tool compared to traditional research methods; identifying the ethical issues involved with neuromarketing research; presenting the main neuromarketing techniques that are being used for the development of marketing research; and presenting studies in which neuromarketing research techniques were used and identifying the main limitations of neuromarketing.

In the identification of the main definitions of neuromarketing, it was observed that the term has been described as a field of neuroscience or, more precisely, a sub-area of neuroeconomics. It has also been represented as a tool for commercial purposes and as an instrument for the acquisition of scientific knowledge. There is still great difficulty in defining what does and does not belong to the field of neuromarketing research. It is clear that there is an overlap with some areas of interest in marketing, such as studies classified by the authors as belonging to neuroeconomics, neurofinance, or social neuroscience. Neuromarketing was identified as a form of marketing research in which conscious and subconscious aspects of the neural and physiological responses of participants are assessed to solve marketing problems.

Neuromarketing was identified as an important tool to help clarify and understand consumers' behaviour, having great potential in the area of communication, as well as the potential to identify consumers' subconscious needs and thus create more attractive packaging, pricing decisions and more efficient brand positioning strategies. In general, the 
great importance of neuromarketing lies in the ability to fill the gaps left by traditional marketing research, such as in-depth qualitative research and focus groups.

Among the advantages of neuromarketing over traditional marketing research methods, neuromarketing does not depend on the consumer's ability or desire to report emotions. Another valuable element of neuromarketing research is the simultaneity of information records with the identification of emotions processed in fractions of a second, which enables the demonstration of the triggering factor of this particular emotion.

The main ethical issues involving neuromarketing are the violation of the privacy and autonomy of the consumer. Another ethical issue found is the presence of physicians and academics conducting neuromarketing research for commercial purposes. Concern regarding the exploitation of vulnerable groups, such as children, was also identified as an ethical issue.

Concerning neuromarketing techniques, functional magnetic resonance (fMRI) was the technique that most attracted the attention of scientists and companies. Other commonly used techniques include electroencephalography, which is widely used to determine the effect of each element from television ads, and eye tracking and galvanic skin response (GSR) measurement. Other techniques presented, but used less frequently by research and consulting firms, include positron emission tomography (PET), magnetoencephalography (MEG), facial recognition, and the measurement of cardiovascular parameters and neuroimmunoendocrinological activities.

Experiments were found using these techniques in the areas of marketing related to advertising and publicity, elements of communication, new product development, packaging, pricing and promotion strategies, brand positioning and the forecasting of consumer choices. Finally, some limitations were identified. Many neuromarketing experimental results are inaccurate and biased. Furthermore, there is a high cost in the development of neuromarketing research, which leads to experiments with small samples that limit generalisability. Moreover, there is not a framework to relate the marketing stimuli to the emotions processed and the brain areas activated.

In conclusion, it was seen that the presence of neuromarketing as a marketing research tool and people's interest in this field of science have increased in recent years. With more studies about neuromarketing being conducted and their results disseminated, it is possible that more companies will join the neuromarketing efforts to have better designed products and more effective advertising. Therefore, neuromarketing efforts can help the understanding of many kinds of complex buying behavior. For example, one does not fully understand what types of "triggers" lead individuals to use their intuition in certain situations, but not in other ones. The comprehension of what rationality or irrationality levels occur in consumption decisions can also be enhanced. The better understanding of the brain cognitive mechanisms by means of the new technologies discussed in this article has the potential to explain many of the major issues which marketers seek the answers. 


\section{References}

Ariely, D., \& Berns, G. S. (2010). Neuromarketing: The hope and hype of neuroimaging in business. Nature Reviews Neuroscience, 11(4), 284-292. http://dx.doi.org/10.1038/nrn2795

Babiloni, F. (2012). Consumer neuroscience: A new area of study for biomedical engineers. IEEE Pulse, 3(3), 21-23. http://dx.doi.org/10.1109/MPUL.2012.2189166

Banks, S. J., Bellerose, J., Douglas, D., \& Jones-Gotman, M. (2012). Bilateral skin conductance responses to emotional faces. Applied Psychophysiology and Biofeedback, 37(3), 145-152. http://dx.doi.org/10.1007/s10484-011-9177-7

Bardin, L. (1977). Análise de conteúdo. Lisboa, Portugal: Edições 70.

Bercea, M. D. (2013). Quantitative versus qualitative in neuromarketing research. Munich Personal RePEc Archive, 44134, 1-12.

Butler, M. J. (2008). Neuromarketing and the perception of knowledge. Journal of Consumer Behaviour, 7(4-5), 415-419. http://dx.doi.org/10.1002/cb.260

Crease, R. P. (1991). Images of conflict: MEG vs. EEG. Science, 253(5018), 374-375.

Dinu, G., Tanase, A. C., Dinu, L., \& Tanase, F. (2010). The new techniques for handling consumer behaviour. Proceedings of the International DAAAM Symposium, 21(1), 1115-1116.

Dooley, R. (2010). Brandwashing? Retrieved from http://www.neurosciencemarketing.com/blog/articles/brandwashing.htm

Eser, Z., Isin, F. B., \& Tolon, M. (2011). Perceptions of marketing academics, neurologists and marketing professionals about neuromarketing. Journal of Marketing Management, 27(7-8), 854-868. http://dx.doi.org/10.1080/02672571003719070

Fisher, C. E., Chin, L., \& Klitzman, R. (2010). Defining neuromarketing: Practices and professional challenges. Harvard Review of Psychiatry, 18(4), 230-237. http://dx.doi.org/10.3109/10673229.2010.496623

Fugate, D. L. (2007). Neuromarketing: A layman's look at neuroscience and its potential application to marketing practice. Journal of Consumer Marketing, 24(7), 385-394. http://dx.doi.org/10.1108/07363760710834807

Fugate, D. L. (2008). Marketing services more effectively with neuromarketing research: A look into the future. Journal of Services Marketing, 22(2), 170-173. http://dx.doi.org/10.1108/08876040810862903

Garcia, J. R., \& Saad, G. (2008). Evolutionary neuromarketing: Darwinizing the neuroimaging paradigm for consumer behavior. Journal of Consumer Behaviour, 7(4-5), 397-414. http://dx.doi.org/10.1002/cb.259

Green, S., \& Holbert, N. (2012). Gifts of the neuro-magi: Science and speculation in the age of neuromarketing. Marketing Research, 24(1), 10-14. 
Hubert, M. (2010). Does neuroeconomics give new impetus to economic and consumer research? Journal of Economic Psychology, 31(5), 812-817. http://dx.doi.org/10.1016/j.joep.2010.03.009

Hubert, M., \& Kenning, P. (2008). A current overview of consumer neuroscience. Journal of Consumer Behaviour, 7(4-5), 272-292. http://dx.doi.org/10.1002/cb.251

Javor, A., Koller, M., Lee, N., Chamberlain, L., \& Ransmayr, G. (2013). Neuromarketing and consumer neuroscience: Contributions to neurology. BMC Neurology, 13(1), 1-12. http://dx.doi.org/10.1186/1471-2377-13-13

Kline, J. (2004). Frontal EEG asymmetry, emotion, and psychotherapy: The first, and the next 25 years. Biological Psychology, 67(1-2), 1-5.

Lee, N., Broderick, A. J., \& Chamberlain, L. (2007). What is 'neuromarketing'? A discussion and agenda for future research. International Journal of Psychophysiology, 63(2), 199-204. http://dx.doi.org/10.1016/j.ijpsycho.2006.03.007

Lin, C. H., Tuan, H. P., \& Chiu, Y. C. (2010). Medial frontal activity in brand-loyal consumers: A behavior and near-infrared ray study. Journal of Neuroscience, Psychology, and Economics, 3(2), 59-73. http://dx.doi.org/10.1037/a0015461

Lindstrom, M. (2009a). A lógica do consumo: Verdades e mentiras sobre por que compramos (M. Lino, Trad.). Rio de Janeiro, RJ: Nova Fronteira.

Lindstrom, M. (2009b). Buyology: A ciência do neuromarketing. Lisboa, Portugal: Gestão Plus.

Marci, C. D. (2008). Minding the gap: The evolving relationships between affective neuroscience and advertising research. International Journal of Advertising, 27(3), 473-475.

Marcus, G. (2012). Neuroscience fiction. Retreived from http://www.newyorker.com/online/blogs/newsdesk/2012/12/what-neuroscience-really-teache s-us-and-what-it-doesnt.html

McClure, S. M. et al. (2004) Neural correlates of behavioral preference for culturally familiar drinks. Neuron, v. 44, p. 379-387.

Melillo, W. (2006). Inside the consumer mind: What neuroscience can tell us about marketing. Adweek, 47(3).

Morin, C. (2011). Neuromarketing: The new science of consumer behavior. Society, 48(2), 131-135. http://dx.doi.org/10.1007/s12115-010-9408-1

Murphy, E. R., Illes, J., \& Reiner, P. B. (2008). Neuroethics of neuromarketing. Journal of Consumer Behaviour, 7(4-5), 293-302. http://dx.doi.org/10.1002/cb.252

Nenad, D. H. (2011). Emotional marketing: Eye-tracking and brain measuring: Using neuromarketing to sell newspapers. Editor \& Publisher, 144(1). 
Ohme, R., \& Matukin, M. (2012). A small frog that makes a big difference: Brain wave testing of TV advertisements. IEEE Pulse, 3(3), 28-33. http://dx.doi.org/10.1109/MPUL.2012.2189169

Orzán, G., Zara, I. A., \& Purcarea, V. L. (2012). Neuromarketing techniques in pharmaceutical drugs advertising. A discussion and agenda for future research. Journal of Medicine and Life, 5(4), 428-432.

Page, G. (2012). Scientific realism: what 'neuromarketing' can and can't tell us about consumers. International Journal of Market Research, 54(2), 287-290.

Perrachione, T. K., \& Perrachione, J. R. (2008). Brains and brands: Developing mutually informative research in neuroscience and marketing. Journal of Consumer Behaviour, 7(4-5), 303-318. http://dx.doi.org/10.1002/cb.253

Pickersgill, M. (2013). The social life of the brain: Neuroscience in society. Current Sociology, 61(3), 322-340. http://dx.doi.org/10.1177/0011392113476464

Reynolds, J. (2006). Editorial. Journal of Targeting, Measurement and Analysis for Marketing, 14(3), 189-190. http://dx.doi.org/10.1057/palgrave.jt.5740180

Senior, C., \& Lee, N. (2008). Editorial: A manifesto for neuromarketing science. Journal of Consumer Behaviour, 7(4-5), 263-271. http://dx.doi.org/10.1002/cb.250

Schneider, T., \& Woolgar, S. (2012). Technologies of ironic revelation: enacting consumers in neuromarkets. Consumption Markets \& Culture, 15(2), 169-189. http://dx.doi.org/10.1080/10253866.2012.654959

Vecchiato, G., Kong, W., Maglione, A., \& Wei, D. (2012). Understanding the impact of TV commercials: Electrical neuroimaging. IEEE Pulse, 3(3), 42-47. http://dx.doi.org/10.1109/MPUL.2012.2189171

Wilson, R., Gaines, J., \& Hill, R. P. (2008). Neuromarketing and consumer free will. Journal of Consumer Affairs, 42(3), 389-410. http://dx.doi.org/10.1111/j.1745-6606.2008.00114.x

Zaltman, G. (1997). Rethinking market research: Putting people back in. Journal of Marketing Research, 34(4), 424-437. http://dx.doi.org/10.2307/3151962 